\title{
Editorial
}

doi:10.1017/S0954102014000224

\section{New ideas for funding science}

$\mathrm{T}$ he global recession has had many unfortunate effects at national, regional and local levels. Predictably, many governments have abandoned their rather half-hearted efforts to deal with the mitigation of global change on the grounds that present poverty is more important than the potential damage we predict for the future. One obvious example of this false economy has been the widespread and costly damage caused in the UK by flooding this winter, much of which was preventable if the planned flood defence programmes had not been cancelled.

Into this maelstrom of unemployment, underinvestment and economic inequality what has happened to science funding when people are losing their homes and companies are going bankrupt? Actually, the picture is mixed with some countries, like China and South Korea, investing substantially more in research, including Antarctic research. Others, according to OECD figures, like the United Kingdom, have reduced their percentage spend, either by direct cuts or by allowing inflation to reduce its value.

And it is certainly more difficult than usual to defend the need for expensive Antarctic research. Yet we need to fight that battle with vigour to show that our work is both relevant and needed now to help plan for a predicted future that is becoming more threatening by the year. Antarctic data is and will continue to be crucial both for modelling the future world and for working out what strategies we will need to develop to cope with rising sea level, falling fish harvests, increasing extreme meteorological events and failing crops.

Yet we also need to be inventive if the treasuries of the world want to limit what we can do in future - so what else can we try to make more science from less government money?

New Zealand has taken the bold step of creating a virtual Antarctic Institute and begun using foundation funding and commercial sponsorship to supplement funding. In some respects, this must seem rather like the funding profiles for some of the early expeditions except that these days there is a need for long-term commitment that might be hard to find. Perhaps steps like this will in time result in commissioned research?

What about crowd funding for research? Crowd funding through the web has certainly proved successful for a variety of artistic and economic ideas. Would it work for science? There have been a number of attempts through platforms such as Experiment, Petridish and Kickstart and, if they have demonstrated anything, it is that sourcing funds this way needs a quite different approach to applying for government grants. A group at Lisbon University was recently successful in raising over 21000 euro for permafrost research in the South Shetland Islands but it would seem you need to offer a range of feedbacks to funders, not unlike the way Ernest Shackleton named Antarctic features after his sponsors!

A different approach has been the Spirit of Mawson expedition - a privately financed and organised scientific expedition to commemorate the first Australian Antarctic Expedition of 1914. The mixing of tourists with scientists was apparently necessary to make the economics work. Sadly, the ship became stuck in the ice but the ensuing media coverage stimulated a global discussion about the advisability of this novel approach.

Finally, there has been increasing interaction between scientists and IAATO, with tourist ships providing free travel for individuals and for some cargo, defraying costs that would otherwise be borne by the National Operators.

Keeping an open mind on funding is clearly crucial as money becomes tighter. Whilst none of these offer a complete answer perhaps all of them have a part to play in the future?

D.W.H. WALTON 